Produto \& Produção, vol. 17 n.4, p.1-18, dez. 2016

RECEBIDO EM 17/03/2016. ACEITO EM 26/11/2016.

Felipe Rodrigues da Silva

Fundação Oswaldo Cruz-Fiocruz

felipe.rodrigues@gpi.ufrj.br

Heitor Mansur Caulliraux

Pontifícia Universidade Católica do Rio de Janeiro - PUC-Rio

heitor@gpi.ufrj.br

\title{
A Desverticalização no Setor de Produção de Biomedicamentos e a Utilização das Empresas CMOs (Contract Manufacturing Organization)
}

\begin{abstract}
Resumo
Esse trabalho consiste em um estudo sobre o panorama atual do setor de produção de biomedicamentos, em especial quanto ao movimento de desverticalização identificado em empresas da área, buscando entender como esse processo está ocorrendo, em que parte do ciclo produtivo ele está acontecendo mais frequentemente e que fatores e circunstâncias estão impulsionando esse fenômeno. A decisão entre fazer internamente ou terceirizar uma atividade pode ser considerada altamente estratégica para uma companhia, sobretudo quando se trata de atividades finalísticas. Nesse contexto, estão surgindo cada vez mais empresas do tipo CMO (Contract Manufacturing Organization), especializadas na prestação de serviços de produção. A metodologia de pesquisa utilizou como principais fontes as informações coletadas em revisão de literatura e as percepções obtidas em entrevistas semi-estruturadas realizadas em campo com especialistas que atuam na alta direção em organizações da área.
\end{abstract}

Palavras chave: Terceirização; Biomedicamentos; Produção

\begin{abstract}
This work is a study on the current situation of the biopharmaceutical production sector, especially regarding the outsourcing movement identified in the area companies, seeking to understand how and in which part of the production cycle this process is taking place and the factors and circumstances that are driving this phenomenon. The decision between doing internally or outsource an activity can be considered highly strategic to an organization, especially when it comes to core activities. In this context, the CMO companies (Contract Manufacturing Organization), specialized in production services, are actually increasing. The research methodology used the information collected in a literature systematic review and the insights obtained from semi-structured interviews with experts who work in high-ranking of the organizations of the area.
\end{abstract}

Key-words: Outsourcing; Biopharma; Manufacturing. 
A partir do fim da Segunda Guerra Mundial, uma vertente biotecnológica começou a apresentar papel significativo no campo da indústria farmacêutica. As décadas seguintes foram de expansão, porém somente a partir da segunda metade dos anos 80 as empresas de biotecnologia cresceram a ponto de começarem a lançar no mercado seus próprios produtos. Nessa época a Amgen, por exemplo, lançou em 1989 o produtor de glóbulos vermelhos eritropoetina (Epogen). Assim, alguns biomedicamentos alcançaram patamares de venda superiores a U\$\$100 milhões, despertando de vez o interesse das indústrias farmacêuticas tradicionais por drogas produzidas por processos biotecnológicos. O Boston Consulting Group, em seu levantamento de 1980, identificou que apenas $2 \%$ do total de pesquisas efetuadas pelas indústrias farmacêuticas norte-americanas situava-se no campo da biotecnologia, enquanto que 1993, o percentual já era de 34\% (WONGTSHOWSKI, 2007).

Ao longo dos anos o setor farmacêutico tem experimentado diversas transformações motivadas por movimentos de fusões, aquisições, desverticalização - subcontratação de operações realizadas externamente, dentre outros. As transformações em curso têm como características principais a globalização, a concentração, a especialização e a descentralização geográfica. A globalização é reflexo da mobilidade de capital, da revolução nas comunicações e da abertura de mercados. Como consequência, a indústria padronizou seus produtos fazendo com que não ocorra necessariamente relação geográfica entre cliente e fornecedor. Já a concentração é o processo de criação através de fusões, por exemplo, de empresas de grande porte que se beneficiam basicamente do poder de escala. A especialização faz com que algumas empresas, sobretudo as pequenas start-ups, foquem sua atuação na descoberta de novos produtos específicos e posteriormente os negociem para companhias maiores. A descentralização geográfica é um fenômeno relativamente novo, onde a produção tende a migrar para países onde há insumos e mão de obra excedente, reduzindo, portanto, seus custos (FRANÇOSO \& STRACHMAN, 2013).

A fabricação de drogas e medicamentos foi culturalmente verticalizada na indústria farmacêutica, com as empresas optando por produzir tudo internamente sem a utilização de terceiros. Os executivos apostavam que as prioridades da empresa podiam ser mudadas e recursos realocados rapidamente, já que eram provenientes dos próprios meios de produção e controlados exclusivamente pela companhia. Entretanto, a situação mudou, com recursos internos cada vez mais escassos e diversas drogas expirando patentes, acirrando a competição entre as empresas da área. Motivados por este cenário, as companhias farmacêuticas têm realizado diversos movimentos, objetivando ganho de competitividade. Dentre esses, está o estabelecimento de parcerias de terceirização com empresas prestadoras de serviços (CHATURVEDI, 2008). Recentemente, o mercado de "outsourcing" tem sido tão atraente que mesmo as grandes empresas farmacêuticas (Sanofi, GSK, Novartis, Merck, etc.) estão construindo plantas fabris como unidades de negócios autônomas capazes de atender a própria instituição ou oferecer serviços externos (SCHACHTER, 2012). Assim, uma mesma organização pode atuar como contratada e contratante, conforme definido na sua estratégia e de acordo com as oportunidades de mercado.

O mercado de biomedicamentos segue, de uma maneira geral, dinâmica semelhante ao de farmoquímicos. Porém, enquanto no mercado farmoquímico as grandes empresas lideram uma dinâmica competitiva, no biotecnológico existe uma complementaridade entre organizações de menor porte, altamente intensivas em tecnologia, com companhias de grande porte (COPANI \& URGO, 2012). Dentre as razões, está o elevado grau de incerteza e riscos presentes no campo da biotecnologia, a dificuldade em completar todas as fases de descoberta e estudos clínicos até o registro do produto por conta das rígidas exigências regulatórias, o elevado grau de capacitação exigido para operação na área e a necessidade de logística eficiente de produção, distribuição e comercialização desses produtos (REZAIE et al.,2008).

A indústria de biofarmacêuticos não somente se converteu em uma fonte importante de novos medicamentos, como também se tornou estratégica do ponto de vista social e econômico. Atualmente é um dos motores de crescimento, gerador de conhecimento e emprego na área tecnológica (MADEIRA, 2013). As moléculas biotecnológicas, geralmente grandes e complexas, têm oferecido não somente novas opções para doenças tratadas com drogas farmoquímicas (moléculas simples e pequenas), como também para a prevenção e tratamento de patologias anteriormente incuráveis. Os 
produtos biológicos têm concedido valiosas opções para prevenção e tratamento de algumas das doenças mais complexas e de grande incidência como esclerose múltipla, mal de Alzheimer, a leucemia linfocítica crônica, diversos tipos de câncer, infecções, dentre muitas outras enfermidades.

A tecnologia para produção de biomedicamentos envolve o uso de organismos vivos, atenuados ou inativados, inteiros ou em subunidades, geneticamente modificados ou não, para produção de vacinas ou proteínas terapêuticas em quantidades industriais. A fabricação de biomedicamentos requer um desafio tecnológico extraordinário, envolvendo atividades complexas que contemplam processos de bioreação sofisticados, sistemas de purificação de alto desempenho, controle de qualidade com metodologias altamente sensíveis, dentre outras abordagens (BAETAS, 2004). Atualmente alguns biomedicamentos já podem ser considerados recordistas em vendas. Entre 2007 e 2013 essa área cresceu em uma taxa média de 14\% ao ano, com valor estimado em 2013 de US\$197 bilhões, correspondendo a aproximadamente $20 \%$ do mercado farmacêutico total. Até 2018, a expectativa é para um valor de US\$344 bilhões, o que corresponderia a aproximadamente $27 \%$ do total do mercado farmacêutico global. No mercado biotecnológico, o setor que cresce mais rapidamente é o de anticorpos terapêuticos, cuja previsão de vendas é de US\$120 bilhões para 2018 (ZHANG, 2015).

Nesse cenário altamente competitivo, considerando os elevados investimentos necessários para o desenvolvimento de produtos biotecnológicos, as empresas têm buscado estratégias e alternativas voltadas, para a minimização de custos e redução dos riscos do negócio. Assim, as companhias têm utilizado de diversos subterfúgios como, por exemplo, a participação em intrincadas redes tecnológicas ou o estabelecimento de parcerias para terceirização de atividades (BAETAS, 2004). O surgimento da possibilidade do emprego de recursos de maneira mais eficiente, baseado nos variados serviços prestados por fabricantes terceirizados, fornece à indústria biofarmacêutica uma flexibilidade não disponível em épocas anteriores. Assim, a adoção da terceirização de atividades para o desenvolvimento ou fabricação de biomedicamentos, respectivamente em empresas do tipo CROs (Contract Research Organization) ou CMOs (Contract Manufacturing Organization), pode representar uma alternativa interessante em diversas circunstâncias.

Nessa área, as parcerias para terceirização tendem a ocorrer desde as fases iniciais do ciclo de vida de um produto, como na descoberta de um princípio ativo, até as etapas de produção em escala industrial para comercialização (SCHACHTER, 2012). A busca estratégica pelos serviços de terceirização é impulsionada por uma série de circunstâncias que incluem esforços para a redução dos custos, ausência de capacidade para produção interna, divisão de responsabilidades, melhoria da produtividade, atendimento aos prazos, atendimento aos requisitos regulatórios, acesso à competências externas do parceiro, dentre outros (SPECIAL REPORT, 2011). A opção pela desverticalização pode também evitar investimentos elevados antes que a aprovação de um novo medicamento esteja assegurada. Ao utilizar tal estratégia, uma empresa pode, por exemplo, adiar a construção de uma planta até que uma nova droga tenha registro regulatório concedido (Figura 1). 


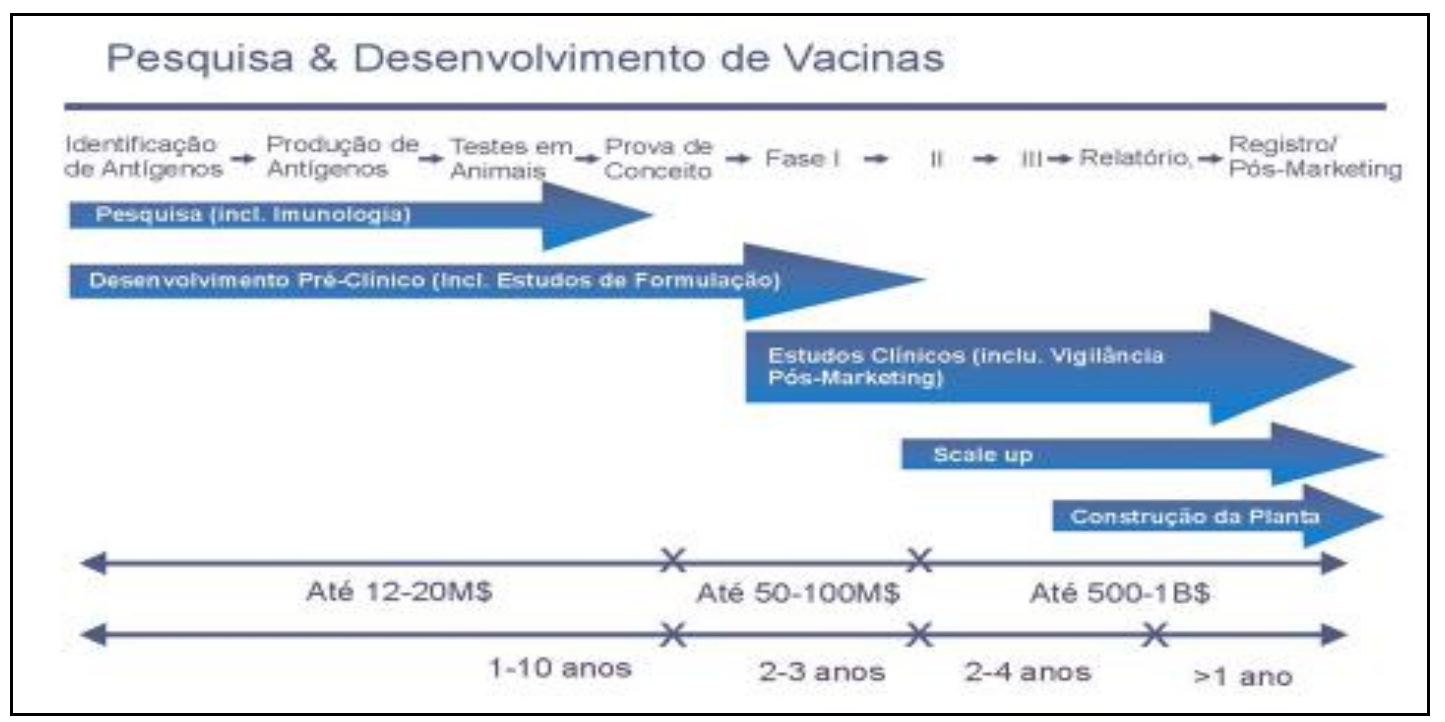

Figura 1 - Cadeia de pesquisa, desenvolvimento e produção de medicamentos Fonte: BARBOSA (2009)

A maioria das atividades terceirizadas na área de biomedicamentos ainda está voltada para o desenvolvimento de linhagens celulares, bioanálises, caracterização de produtos e testes de biossegurança. Contudo, tem-se verificado uma demanda crescente por serviços relacionados à produção industrial, tanto nas grandes quanto nas pequenas empresas farmacêuticas, especializadas em P\&D (startups) e interessadas em testar potenciais produtos em fase final de desenvolvimento. As empresas de biotecnologia, que quase duplicaram nos últimos cinco anos, contribuem para esta tendência principalmente porque procuram maneiras de trazer os seus produtos para o mercado sem realizar investimentos de capital significativos em suas instalações de produção (CHATURVEDI, 2008).

O foco deste estudo é prioritariamente as parcerias para terceirização realizadas com $C M O$ s para fabricação de biomedicamentos em escala industrial. Considerando o ciclo de vida de um biomedicamento, as atividades em larga escala contemplam o scale-up do processo e produção dos lotes para estudos clínicos de fase III (etapas pré-registro), a fabricação do insumo farmacêutico ativo (IFA) para comercialização e o processamento final (basicamente formulação, envase, rotulagem e embalagem) dos lotes para comercialização. Além das etapas de produção propriamente dita, é fundamental que as CMOs ofereçam os serviços de suporte aos lotes fabricados, tais como estudos de estabilidade, controles de qualidade do produto e registro nos órgãos regulatórios correspondentes (NEHA et al.,2012). Atualmente já é possível encontrar CMOs que possuem instalações certificadas e equipes especializadas no estabelecimento de processos tanto em células bacterianas, quanto em células de mamíferos, com volumes a serem escalonados desde a bancada até fermentadores e biorreatores de milhares de litros. A Figura 2 apresenta alguns dos serviços oferecidos pelas empresas CMOs. 


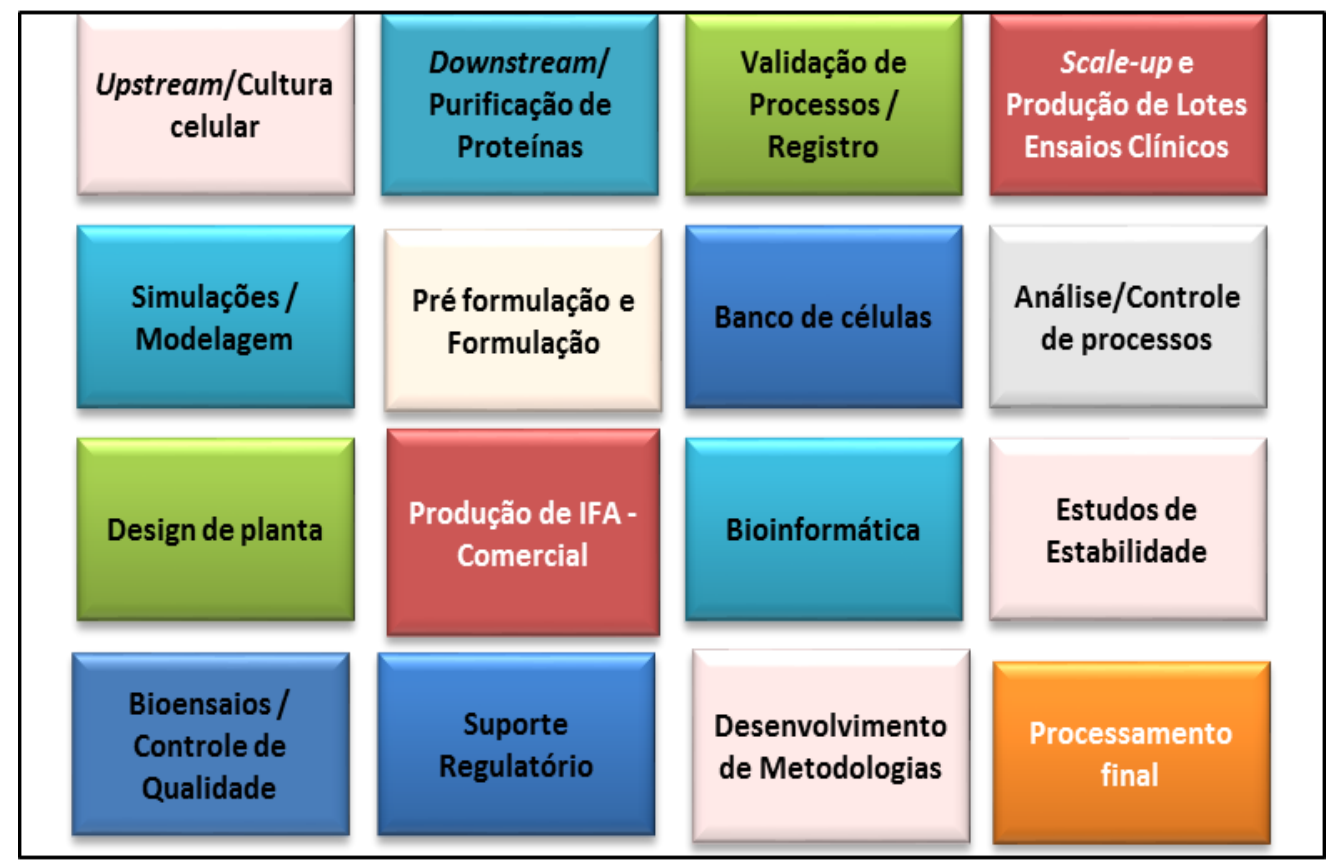

Figura 2 - Atividades oferecidas por empresas $C M O$ s prestadora de serviços na área de biomedicamentos

Fonte: Elaboração própria

Estima-se que o mercado global de terceirização na área de biofarmacêuticos gire em aproximadamente US\$4,9 bilhões de dólares, tendo crescido entre 2009 e 2013 numa taxa de aproximadamente $11 \%$ ao ano. A expectativa é que esse negócio experimente uma taxa de crescimento anual de 14,5\% no período entre 2014 e 2018, chegando próximo a um valor total de mercado de US\$10 bilhões em 2018. Estima-se que em 2018 a utilização média de serviços terceirizados pela indústria biofarmacêutica responda por 12\% das atividades totais (ZHANG, 2015).

No Brasil, a prática da terceirização não é observada com frequência na fabricação de biomedicamentos, uma vez que ainda existem poucas empresas com capacidade de produção certificadas pelos órgãos regulatórios e com as competências necessárias atuando nessa área. Porém, esse movimento vem se tornando cada vez mais frequente na produção de compostos sintéticos (farmoquímicos). Com base na demanda no mercado interno, muitos laboratórios contratam empresas do setor para complementar suas linhas para produção de efervescentes, comprimidos, xaropes, produtos injetáveis, embalagens, dentre outros (SCARAMUZZO, 2012).

Considerando o panorama descrito, a proposta desse estudo foi estudar detalhadamente o setor de produção de biomedicamentos global, em sua atual complexidade, em especial quanto ao seu processo contemporâneo de desverticalização, onde diversas organizações da área têm transferido para empresas CMOs seus processos de produção em larga escala.

\section{Considerações Metodológicas}

Para o desenvolvimento da pesquisa foram adotados procedimentos múltiplos. Inicialmente foi realizada uma pesquisa bibliográfica sobre a ocorrência do fenômeno de desverticalização em organizações biofarmacêuticas, o emprego das empresas CMOs em atividades do setor e as peculiaridades existentes no mercado global de biomedicamentos.

A busca por fontes de interesse na literatura ocorreu da seguinte maneira:

- $\quad$ Pesquisas por palavras-chaves (Outsourcing, Manufacturing, Biotech e Pharma) em bases de periódicos (as principais foram Scielo, Science Direct, Web of Science, Emerald e Pubmed);

- $\quad$ Levantamento de relatórios ou publicações em organizações especializadas;

- $\quad$ Referências sugeridas em disciplinas cursadas pelo pesquisador;

- $\quad$ Buscas por livros em sites especializados;

- $\quad$ Recomendações de entrevistados, pesquisadores e profissionais da área; 
Após o levantamento de informações na literatura, foi proposta uma metodologia para coleta de dados e percepções em um estudo de campo. Quanto aos objetivos, a pesquisa realizada pode ser classificada como explanatória, pois identifica fatores ou circunstâncias que ocasionam um fenômeno, no caso a desverticalização das atividades produtivas observada em indústrias de biomedicamentos, explicando o "porquê" dele acontecer ou ter acontecido. Isso ocorre quando as circunstâncias que estimulam o movimento são debatidas em entrevistas semi-estruturadas com especialistas atuando em posições centrais em empresas biofarmacêuticas. Quanto à natureza, esse estudo pode ser caracterizado como aplicado, uma vez que tem por objetivo auxiliar decisões gerenciais do tipo "comprar ou fazer", consideradas fundamentais em organizações da área (SILVA \& MENEZES, 2001). Sobre a abordagem utilizada, pode-se considerar que a coleta de informações e percepções foi realizada de forma qualitativa. Investigativa e profunda por natureza, a pesquisa qualitativa é a mais indicada para captar aspectos relacionados à percepção dos indivíduos sobre um tema. A técnica qualitativa foi também escolhida, pois evita que pessoas não conhecedoras do tema respondam à pesquisa, protegendo os dados de um preocupante viés (WOLFF, 2010).

A seleção da amostra foi realizada de acordo com critérios pré-estabelecidos pelo pesquisador. Inicialmente, foram levantados os atores e as principais organizações que se enquadravam aos interesses da pesquisa. Nesse estudo considerou-se como população alvo, gestores especialistas atuando no alto escalão da indústria de biomedicamentos. Os principais critérios adotados na seleção dos entrevistados foram experiência na área, visão sistêmica de mercado e cargo ou função exercida em organizações do setor biofarmacêutico. No momento do contato, o pesquisador se identificava, assim como fornecia informações sobre o tema de pesquisa, seus objetivos e a forma de participação do entrevistado.

A coleta de informações foi realizada com gestores especialistas lotados em companhias de diversos tipos, tais como públicas, privadas, nacionais, transnacionais, agências regulatórias, dentre outros. O pesquisador foi parte integrante desse processo, uma vez que foi a campo como entrevistador para coletar as informações fornecidas pelos participantes. Quanto à forma de abordagem utilizada em campo, os especialistas foram entrevistados de forma semi-estruturada, seguindo um roteiro previamente estabelecido. Neste tipo de entrevista, o pesquisador tem um conjunto de questões pré-definidas, mas dispõe de liberdade para abordar situações cujo interesse surja no decorrer da entrevista. As questões pré-definidas serviram como diretrizes, mas não ditaram de maneira rígida a forma como a entrevista transcorreu. $\mathrm{O}$ objetivo do pesquisador foi realizar uma combinação de perguntas abertas e fechadas, onde o entrevistado teve a oportunidade de discorrer livremente sobre o assunto. Por ser altamente flexível, essa abordagem possibilita que outras questões desviem ligeiramente do "guia" do entrevistador, além de permitir uma maior diferenciação entre os entrevistados, uma vez que o rumo seguido dependerá, em grande parte, do retorno deles (CANDELORO \& SANTOS, 2006). A tabela 1 apresenta os profissionais entrevistados durante o estudo, o tipo de empresa em que atuam, os cargos que ocupam na companhia e a localização da unidade da organização em que estão lotados. 
Tabela 1 - Entrevistados no estudo em campo

\begin{tabular}{|c|c|c|c|}
\hline Entrevistado & Tipo de Empresa & Cargo & $\begin{array}{l}\text { Localização da } \\
\text { Empresa }\end{array}$ \\
\hline AS & $\begin{array}{c}\text { Nacional privada (joint } \\
\text { venture) }\end{array}$ & Diretor & São Paulo \\
\hline $\mathbf{A C}$ & Nacional pública & Diretor & Rio de Janeiro \\
\hline BC & Transnacional privada & $\begin{array}{c}\text { Gerente de Processos - } \\
\text { Brasil }\end{array}$ & São Paulo \\
\hline $\mathbf{C A}$ & Transnacional privada & $\begin{array}{c}\text { Gerente de Negócios - } \\
\text { Brasil }\end{array}$ & São Paulo \\
\hline JCF & Transnacional privada & Vice-Presidente Brasil & Rio de Janeiro \\
\hline $\mathbf{L P}$ & Agência Regulatória & Chefe de Gabinete & Brasília \\
\hline MO & $\begin{array}{c}\text { Nacional privada (joint } \\
\text { venture) }\end{array}$ & Assessor de Diretor & São Paulo \\
\hline MP & Transnacional privada & $\begin{array}{l}\text { Gerente de Novos } \\
\text { Negócios - Brasil }\end{array}$ & São Paulo \\
\hline RD & Nacional privada & $\begin{array}{l}\text { Assessor Técnico - } \\
\text { Diretor }\end{array}$ & São Paulo \\
\hline TM & Transnacional privada & $\begin{array}{l}\text { Gerente Mundial de } \\
\text { Transferência de } \\
\text { Tecnologia }\end{array}$ & Bruxelas (Bélgica) \\
\hline
\end{tabular}

Fonte: Elaboração própria

Sobre a análise dos dados obtidos em campo, as entrevistas realizadas foram gravadas em áudio - com autorização prévia dos entrevistados por meio de um Termo de Consentimento - e em seguida transcritas. Após cada transcrição, procedeu-se à leitura da entrevista para verificar todas as verbalizações dos entrevistados e destacar os principais pontos passíveis de discussão ou, se possível, complementação com dados quantitativos (NAVARRO, 2015).

Os dados obtidos a partir das entrevistas semi-estruturadas foram descritos da maneira mais detalhada possível e apresentados sempre quando possível em gráficos para facilitar a visualização e análise. O pesquisador procurou ter o cuidado de não unificar as respostas, nem buscar qualquer generalização, pois para muitas questões, houve divergência de opiniões. Tais divergências contribuíram para o enriquecimento desta pesquisa. Faz-se importante lembrar que as pesquisas qualitativas não têm, por definição de método, a capacidade de generalização dos dados coletados, ficando estes restritos à amostra pesquisada.

Além das entrevistas semi-estruturadas, utilizadas como instrumento principal para coleta de informações em campo, aplicou-se também um questionário de suporte com o objetivo de consolidar, acrescentar ou recordar ao participante algo que por ventura não tenha recordado de abordar no transcorrer das entrevistas. O questionário de suporte foi constituído de perguntas fechadas com cinco graus de seleção (Discordo Totalmente, Discordo Parcialmente, Não Sei, Concordo Parcialmente e Concordo Totalmente), cujos objetivos foram testar em que etapas do ciclo de produção de biomedicamentos o fenômeno da desverticalização era mais frequentemente observado e quais fatores e circunstâncias mais influenciavam no acontecimento do mesmo. Os itens avaliados encontram-se apresentados na Tabela 2. 
Tabela 2 - Testes realizados no questionário de suporte

\begin{tabular}{|c|c|}
\hline Testes realizados & $\begin{array}{l}\text { Atividades produtivas desverticalizadas e } \\
\text { Fatores/Circunstâncias de influência }\end{array}$ \\
\hline \multirow{3}{*}{$\begin{array}{l}\text { Teste } 1 \text { - Etapas do ciclo de produção em } \\
\text { que as empresas buscam a desverticalização }\end{array}$} & Atividades de "Scale-Up" \\
\hline & Atividades de produção de IFA \\
\hline & Atividades de processamento final \\
\hline \multirow{10}{*}{$\begin{array}{l}\text { Teste } 2 \text { - Fatores e circunstâncias de } \\
\text { influência na desverticalização }\end{array}$} & Redução de Custos \\
\hline & Foco no Core Business \\
\hline & Velocidade de Produção \\
\hline & Acesso às competências externas \\
\hline & Flexibilidade Operacional \\
\hline & Qualidade \\
\hline & Pontualidade de Entrega \\
\hline & Incorporação de Inovações \\
\hline & Estratégia de Longo Prazo \\
\hline & Mitigação de Riscos \\
\hline
\end{tabular}

Fonte: Elaboração própria

\section{Resultados e Discussão da Pesquisa em Campo}

Conforme disposto anteriormente, para esse estudo dez gestores especialistas na área forneceram suas principais percepções sobre a desverticalização na produção de biomedicamentos. As entrevistas duraram em média entre 30 e 60 minutos e foram realizadas em sua maioria presencialmente ou, em alguns casos, por teleconferências. Ressalta-se que as informações coletadas são oriundas de opiniões pessoais e não necessariamente representam estratégias das empresas em que os entrevistados atuam.

Quanto à ocorrência do fenômeno, todos os entrevistados concordaram que de fato há uma tendência nas organizações da área em terceirizar determinadas operações produtivas, porém ainda restrita a algumas etapas do ciclo de produção. O entendimento da maioria dos entrevistados foi de que o fenômeno acontece mais significativamente nas atividades de "scale-up/produção dos lotes para ensaios clínicos de fase III", seguido pelas etapas de processamento final (formulação, envase, liofilização, embalagem e rotulagem) e com frequencia significativamente menor nas atividades de produção da IFA para comercialização (pós-registro). As percepções obtidas durante as entrevistas e as informações coletadas por meio dos questionários de suporte foram compiladas e encontram-se dispostas na Figura 3. Enquanto 90\% dos entrevistados perceberam a desverticalização nas etapas de "scale-up/produção dos lotes para ensaios clínicos", 70\% apontaram o movimento ocorrendo nas atividades de processamento final e somente $30 \%$ enxergaram a ocorrência na produção da IFA para comercialização.

Esses resultados eram esperados, uma vez que as atividades de "Scale up e produção de lotes para os ensaios clínicos de fase III" acontecem em escala de produção, porém ainda em ocasião anterior ao registro e comercialização do produto. Em função disso, nesse momento ainda há uma 
incerteza considerável sobre a aprovação e registro. Assim, muitas empresas da área optam por desverticalizar essas atividades visando compartilhar os riscos. Já a etapa de processamento final geralmente envolve atividades de menor complexidade tecnológica. Normalmente, essa não é a parte do processo produtivo onde estão envolvidos os maiores segredos industriais e nem as atividades de maior valor agregado. Por outro lado, em razão da elevada complexidade das atividades, das especificidades dos ativos requeridos, da pouca disponibilidade de prestadores capacitados no mercado e dos segredos industriais envolvidos, as empresas geralmente optam por realizar as atividades de produção da IFA para comercialização internamente.

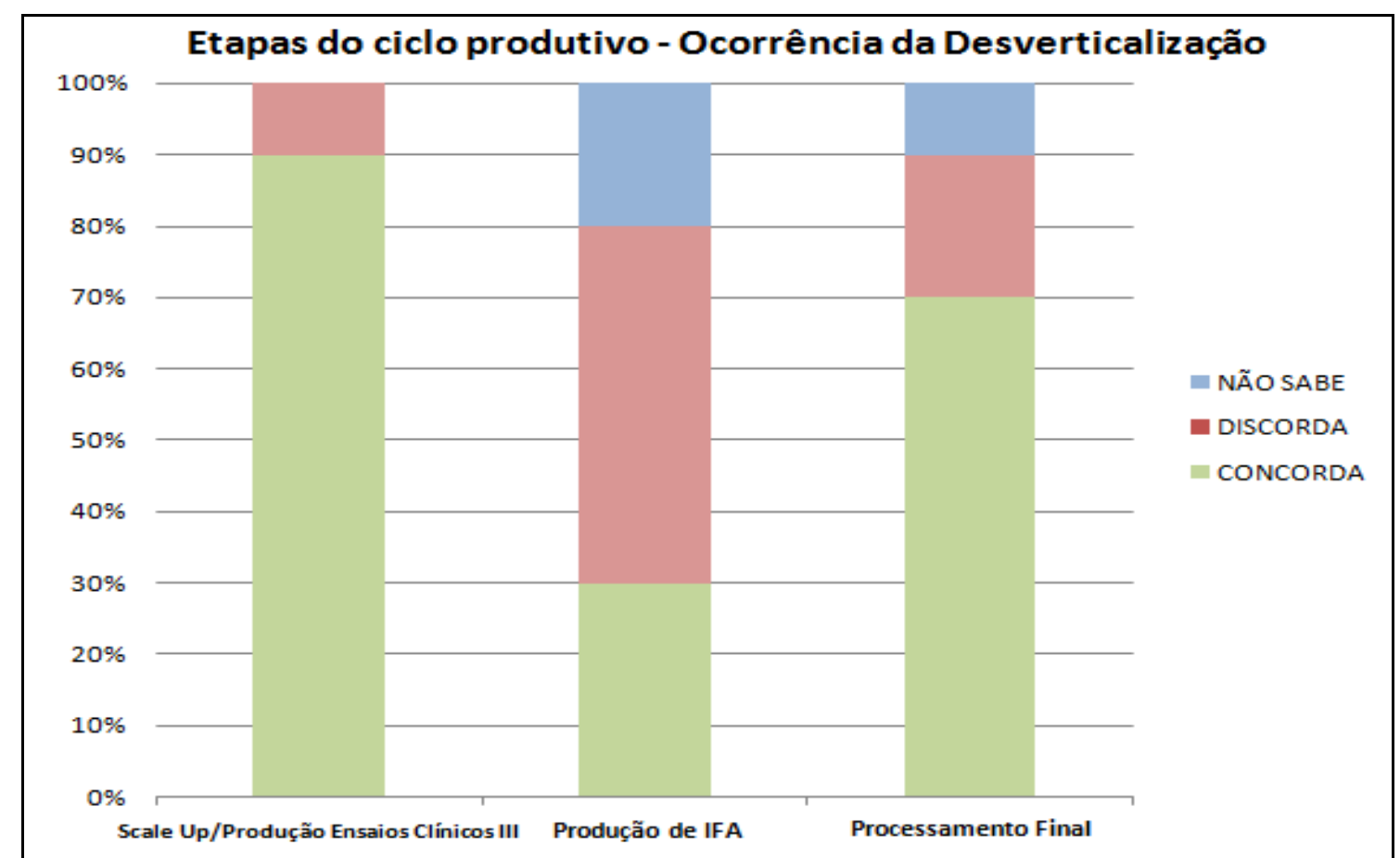

Figura 3 - Percepção dos entrevistados quanto às etapas do ciclo produtivo de biomedicamentos mais frequentemente desverticalizadas

Fonte: Elaboração Própria

O entrevistado BC, assim como grande parte dos outros entrevistados enxerga a desverticalização de biomedicamentos ocorrendo mais frequentemente nas etapas de scale-up e produção dos lotes para ensaios clínicos de fase III (etapas pré-registro do produto). Na visão dele, uma vez as empresas possuindo o registro regulatório, elas optam normalmente por realizar tanto a produção da IFA para comercialização quanto o processamento final internamente. Em algumas ocasiões, por exemplo, o investimento para construção de uma nova fábrica para um biomedicamento ainda em ensaios clínicos pode ser altamente arriscado, já que as instalações prediais são altamente custosas e o sucesso do produto ainda não está garantido.

Já na visão de TM, gerente global de transferência de tecnologia de uma grande transnacional, existe uma tendência à desverticalização de atividades que não façam parte do core business da organização. Para ele, as etapas de processamento final são comumente terceirizadas, porém a produção da IFA é geralmente realizada internamente. Segundo TM, a empresa em que atua não recorre a uma $C M O$ prestadora de serviços para os negócios principais da organização. Isso ocorre apenas para atividades de menor valor agregado.

$\mathrm{Na}$ percepção de $\mathrm{AC}$, diretor de uma instituição pública nacional considerada a maior produtora de imunobiológicos da América Latina, no processamento final há uma tendência mais forte para desverticalização porque não são as atividades que fornecem um maior retorno financeiro. Além disso, na visão dele esta etapa não gera muito valor e nem necessita de um grau de conhecimento tácito significativo devido à menor complexidade das atividades. Na opinião dele uma única fábrica 
com a mesma linha de equipamentos pode atender a múltiplos produtos no que se refere às atividades de processamento final. Tal fato dificilmente ocorrerá para a produção de IFA. Nas etapas de processamento final há um número considerável de prestadores de serviços disponíveis por se tratarem de atividades teoricamente menos complexas. Ele acrescenta ainda que as empresas buscam terceirizar a produção dos lotes para scale-up e ensaios clínicos em ocasiões onde não há espaço ou capacidade nas áreas produtivas destinadas a essa finalidade.

Quanto à desverticalização nas atividades de produção da IFA para comercialização, a maioria dos entrevistados apontou como pouco frequente já que fazem parte do processo onde há um intenso grau de expertise envolvido. Além disso, a alta especificidade dos ativos utilizados nessas atividades pode influenciar na disponibilidade de prestadores de serviços para essa etapa, uma vez que em algumas ocasiões há a necessidade de uma $C M O$ investir alto em um ativo (um bioreator, por exemplo) que possivelmente terá utilidade para uma gama muito restrita de clientes. Na visão de $\mathrm{AC}$, a desverticalização nessa etapa ocorre em ocasiões pontuais, geralmente quando a empresa não tem capacidade ou interesse em produzir internamente. $\mathrm{O}$ entrevistado percebe esse fato claramente quando algumas companhias biofarmacêuticas procuram a empresa gerida por ele interessadas em transferir expertise para que fabrique biomedicamentos para elas (seja por variados modelos de parcerias ou, com menor frequência, através de contratos de terceirização).

Segundo JCF, vice-presidente brasileiro de uma das empresas líderes de mercado, a ocorrência da terceirização mais frequentemente no processamento final não é uma tendência e sim uma resultante. Ele relatou que muitas vezes a empresa onde atua deseja terceirizar a produção de uma determinada IFA, mas não encontra parceiros capacitados no mercado. Deve haver uma decisão estratégica por trás da seleção da empresa para prestação de serviços. Ele alertou sobre a importância das empresas possuírem vínculo com o ambiente acadêmico para que tenham disponibilidade de profissionais aptos e preparados (o que pode demorar um período longo). O desnível de conhecimento entre contratante e contratado não pode ser muito grande, já que é impossível transferir tecnologia sem a intensiva absorção de conhecimento. $\mathrm{Na}$ visão dele, muitas vezes o projeto é estrategicamente desenhado ou alinhado de acordo com as possibilidades do contratado em atendê-lo. Especificamente nesse setor, os riscos associados à manipulação de agentes biológicos infecciosos ou geneticamente modificados, as rigorosas exigências regulatórias consequente disso e a elevada especificidade dos ativos envolvidos nas transações (equipamentos especiais, mão de obra qualificada e alta complexidade de atividades) pode limitar a disponibilidade de empresas de mercado aptas a prestarem esse tipo de serviço.

O entrevistado MP, gerente de produção e marketing de uma conceituada companhia do setor, pontuou sobre a importância de diferenciar o fenômeno ocorrendo nos contextos farmoquímico e biológico. Diferentemente das empresas de biomedicamentos, que normalmente ainda produzem a IFA internamente por consequência da complexidade das atividades envolvidas, as companhias farmoquímicas geralmente já compram a mesma pronta, procedendo internamente ou terceirizando apenas as etapas de processamento final. $\mathrm{O}$ participante $\mathrm{BC}$ relatou não perceber ainda o movimento de terceirização ocorrendo tão intensamente na área de biomedicamentos como na farmoquímica. $\mathrm{Na}$ visão dele, a falta de empresas capacitadas para prestar serviços na área de biomedicamentos ocasiona na realização das etapas de produção internamente. O entrevistado JFC também abordou essa questão. $\mathrm{Na}$ opinião dele, na produção de um farmoquímico há um bom controle do produto final, desde que as variantes do processo estejam corretamente monitoradas. Já na produção de um biofarmacêutico, mesmo que tudo esteja exatamente como o preconizado, há um risco maior envolvido por se tratar de geração de produtos em organismos vivos e, portanto, imprevisíveis.

$\mathrm{Na}$ indústria farmoquímica os processos são geralmente previsíveis e simples de dimensionamento para instalações maiores, ao contrário da biofarmacêutica, que envolve procedimentos e resultados amplamente variáveis. Uma simples instabilidade genética de um organismo hospedeiro, por exemplo, pode alterar a composição molecular do produto gerado (MADEIRA, 2013). Na produção de biomedicamentos, a complexidade advém da produção em sistemas vivos, incluindo organismos patogênicos e/ou geneticamente modificados, e das exigências de ambientes rigorosamente monitorados quanto à qualidade do ar (BARBOSA, 2009). Todos estes fatores influenciam diretamente na dinâmica de movimentação do mercado e no preço dos biomedicamentos que custam em média 10 a 20 vezes mais do que os farmoquímicos (LANTHIER, 2008). 
O entrevistado MP acrescentou que a indústria biofarmacêutica é significativamente custosa. Um investimento mínimo, por exemplo, para a expansão da capacidade produtiva de uma fábrica, requer um aporte financeiro geralmente alto. $\mathrm{O}$ entrevistado observa a utilização de terceirizações em ocasiões pontuais em virtude de alguma epidemia ou situações sazonais. Normalmente as empresas que precisam recorrer à prestação de serviço nessas situações já possuem contratos pré-estabelecidos com $C M O$ s parceiras e capacitadas. Um exemplo dessa situação foi dado pelo entrevistado JCF, sobre a epidemia do vírus HIN1. Segundo ele, havia o conhecimento prévio de que a epidemia aconteceria e, para suprir a demanda esperada, já existia uma rede de instituições parceiras definidas sob contrato para a produção da vacina em massa (o volume de doses partiu do zero para bilhões em poucas semanas). Esses contratos fazem com que ocorra a divisão dos investimentos e dos riscos relacionados ao negócio (na visão dele um dos fatores norteadores para a desverticalização). O mesmo pode ocorrer para as epidemias recentes, como as ocasionadas pelo Zika vírus, caso alguma das vacinas atualmente pesquisadas obtenha registro.

Segundo AC, poucas organizações biofarmacêuticas demonstram interesse e fôlego financeiro para construir uma planta completa para produção de biomedicamentos. O custo fixo de uma fábrica geralmente é muito alto e, se não tiver um portfólio que ocupe a capacidade de produção, incorre-se no risco de subutilização. Atualmente, a empresa dirigida pelo entrevistado estuda oferecer serviços a outras organizações em uma nova planta de protótipos que está em fase final de construção. A viabilidade econômica e os serviços a serem oferecidos estão sendo estudados.

Quanto aos fatores e circunstâncias influentes no fenômeno de desverticalização em empresas da área, as percepções dos entrevistados foram compiladas e apresentadas na Figura 4.

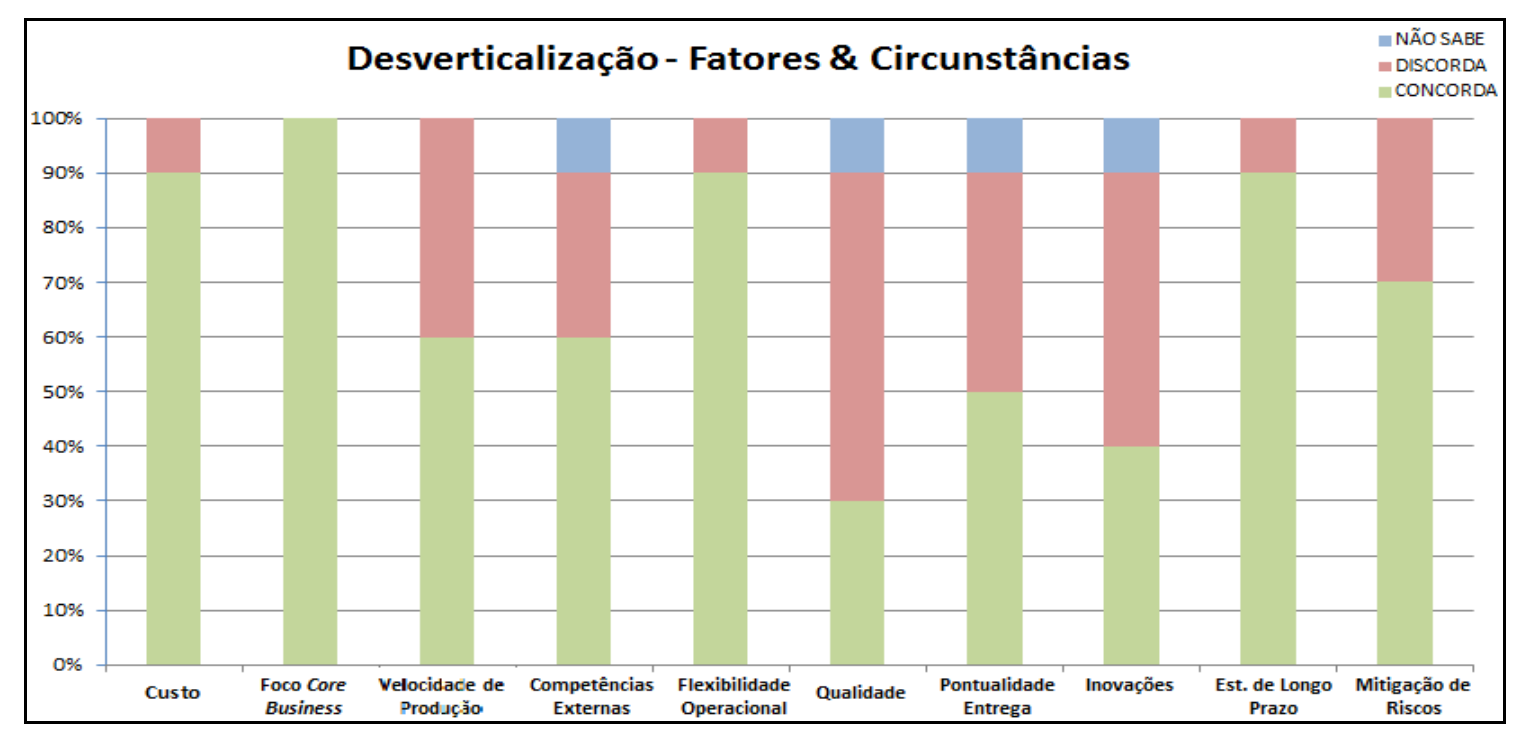

Figura 4 - Percepção dos entrevistados quanto aos fatores e circunstâncias que mais influenciam na desverticalização em etapas produtivas de biomedicamentos

Fonte: Elaboração própria

A totalidade dos entrevistados concordou que a manutenção do foco nas atividades centrais (core business) é um fator fortemente influente. Além disso, a redução dos custos, a flexibilidade operacional, mitigação de risco e a adoção de estratégia de longo prazo também foram fatores significativamente citados pelos entrevistados. A diversidade das informações obtidas sugere que cada empresa vai recorrer ao movimento por circunstâncias que podem variar caso a caso, de acordo com as suas características, especificidades e objetivos. Evidenciou-se ainda que a ocorrência do movimento pode não estar geralmente atrelada a um único fator isolado e sim a um conjunto combinado de fatores e circunstâncias.

É importante ressaltar que embora a maioria dos participantes não tenha enxergado a qualidade como um fator que impulsione diretamente a desverticalização, diversos deles enfatizaram a importância de uma prestação de serviços pautada pela qualidade e pelo atendimento aos aspectos 
regulatórios. Para TM, a empresa contratante precisa ter claro que a responsabilidade pela qualidade do produto final (e a reputação da marca) permanece sendo dela e não da $C M O$. O entrevistado $\mathrm{AC}$ compartilhou da mesma opinião, pontuando sobre a necessidade de certificação da empresa prestadora de serviços pela contratante. AC deu o exemplo da empresa gerida por ele que produz, através de um acordo estabelecido, vacinas para uma grande transnacional da área. Para tanto, a fábrica além de ser inspecionada pelos órgãos regulatórios correspondentes, é periodicamente certificada pela detentora da marca do produto. O entrevistado JCF ressalvou que mesmo não constando o nome da contratante no rótulo do produto, a empresa é considerada corresponsável por ter transferido a tecnologia de produção ao parceiro. Na opinião dele a qualidade deve nortear qualquer modelo de parceria, já que para fazer parte de um cenário global, qualquer empresa precisa possuir as certificações necessárias dependendo da finalidade e o local onde será comercializado o produto. Para ele, é fundamental entender que o dono da demanda só aceita a terceirização porque o parceiro que a supriria endossou a empresa contratada. Se o produto não for fabricado com a qualidade ou no tempo estabelecido, a ruptura com o dono da demanda é provavelmente inevitável. Ele acrescentou ainda que enxerga qualidade na área de produção de biomedicamentos sob dois aspectos principais. O primeiro deles está relacionado à qualidade mínima necessária para atendimento aos locais desejados de maneira segura e eficiente. Por conta desse aspecto, as empresas produtoras conseguem atender à demanda dos países mais pobres sem a necessidade de investimentos muito elevados e resultando em preços mais acessíveis. Por outro lado, para atendimento aos países regulados por órgãos mais rigorosos, tais como EMA (União Européia) ou FDA (Estados unidos), os requisitos de qualidade serão mais rígidos. Consequentemente, os investimentos para produção em consonância com os requisitos regulatórios geralmente envolvem custos mais elevados, resultando em preços maiores.

A estratégia de outsourcing na fabricação de biomedicamentos acrescenta novas variáveis e desafios ao sistema de qualidade da área. Não diferentemente de outros setores, os conflitos entre custo, prazo e qualidade também estão presentes. Historicamente as fronteiras deste sistema eram restritas aos limites das organizações, extrapolado apenas nas auditorias de qualificação de fornecedores geralmente locais. Atualmente o sistema da qualidade precisa suportar não só uma cadeia tecnológica complexa, mas uma rede multi-ramificada envolvendo fornecedores e prestadores de serviços em diversas partes do globo. Se antes o risco sanitário era controlado principalmente por inspeções nas indústrias localizadas no país, hoje parece inviável estar em cada localidade onde um dado produto é fabricado. Para garantir a segurança e a qualidade à população neste cenário global, as autoridades regulatórias buscam melhorar sua atuação. Uma das estratégias tem sido promover uma harmonização dos requisitos regulatórios ao redor do mundo, com o objetivo de possibilitar que uma agência de um dado país reconheça a validade da avaliação realizada pela autoridade regulatória de outro. Para tanto, é preciso que os requisitos sejam similares e que a extensão e profundidade da supervisão regulatória sejam compatíveis.

$\mathrm{Na}$ percepção de $\mathrm{RD}$, diretor de uma grande companhia biotecnológica brasileira, a desverticalização ocorre muitas vezes para complementaridade, onde empresas recorrem ao mercado porque não têm condições ou interesse em realizar internamente. Já BC opinou que muitas organizações procuram as $C M O$ s por não terem estrutura para produzir internamente ou por falta de competências em processos produtivos. Para CA, gerente de negócios de uma grande transnacional da área no Brasil, há uma tendência à desverticalização devido ao aumento da demanda para produção de biomedicamentos no mundo. Na opinião dela, a opção de desverticalizar em muitas ocasiões torna um processo produtivo mais rápido ou econômico do que, por exemplo, ampliar um site fabril ou contratar novos profissionais. Na visão de JCF, alguns elementos podem facilitar ou restringir um dado movimento de terceirização, tais como, o grau de emergência para utilização do biomedicamento, o destino geográfico, o respeito à propriedade intelectual e o atendimento às questões regulatórias.

Quanto aos mecanismos para seleção de uma $C M O$, diversos fatores precisam ser avaliados. Para os entrevistados MO, TM e CA, a escolha deve considerar principalmente a expertise, a reputação, o custo e a capacidade da empresa contratada em absorver uma nova tecnologia para cumprimento de uma dada demanda no prazo desejado. Para isso, deve ser constituída uma equipe de operações industriais e de qualidade dedicadas exclusivamente à transferência de tecnologia. A operação bem sucedida de uma unidade fabril de acordo com os requistos regulatórios, sobretudo quando envolve processos complexos, requer uma significativa compreensão dos procedimentos, além da capacidade de manusear equipamentos e adequar as instalações às condições exigidas. Um grupo 
com profissionais experientes auxilia também na aprovação e registro de um produto nos órgãos regulatórios correspondentes. Para LP, chefe de gabinete da agência regulatória brasileira, durante a escolha de uma $C M O$ deve ser considerada a capacidade de produção disponível na empresa e o certificado de boas práticas de fabricação para plantas industriais de biomedicamentos. A equipe técnica para participação na transferência da tecnologia deve ser composta por profissionais qualificados em processos biotecnológicos com conhecimentos em engenharia de produção, qualidade e assuntos regulatórios de uma forma geral.

Na opinião de MP, a idoneidade e a capacidade de administrar recursos pela empresa $C M O$ avaliada são pontos fundamentais. O entrevistado deu o exemplo da própria organização onde atua que prestou serviços a uma dada empresa na fabricação de quatro produtos farmacêuticos. Segundo ele, embora o custo do serviço tenha sido mais elevado do que em outras companhias, a contratante optou pela empresa onde atua por conta da reputação no mercado. Segundo MP, é importante que as empresas contratantes sigam um procedimento para a seleção de uma $C M O$. Geralmente, abre-se um processo de licitação para terceirização, as informações básicas são encaminhadas às $C M O s$ concorrentes que retornam com a cotação do serviço. Normalmente são selecionadas as três principais, que são auditadas pela contratante, e em seguida a "vencedora" é escolhida (Figura 5). O entrevistado $\mathrm{BC}$ acrescenta ainda que pode ser mais vantajoso selecionar parceiros experientes para viabilizar um dado projeto do que "apostar" em empresas emergentes.

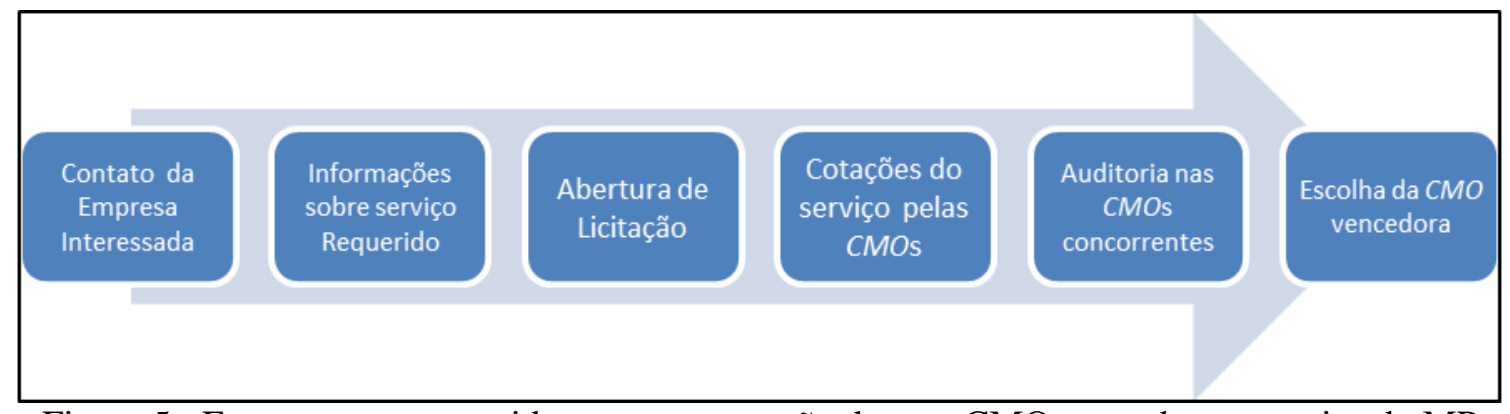

Figura 5 - Etapas a serem seguidas para contratação de uma CMO segundo o entrevistado MP Fonte: Elaboração própria

De acordo com a literatura, os principais itens a serem considerados na contratação de uma $C M O$ são os seguintes (ALKERMES, 2012):

- $\quad$ Tempo e experiência da $C M O$ na área;

- $\quad$ Estrutura para atender ao serviço solicitado;

- $\quad$ Atendimento aos requisitos regulatórios;

- $\quad$ Profissionais capacitados e dedicados;

- $\quad$ Inserção do projeto na estrutura organizacional da $C M O$;

Nessa área, a escolha de uma $C M O$ com instalações apropriadas e que atendam aos rigorosos requisitos de construção, processo e regulatórios para biomedicamentos é um grande desafio. A planta deve ser praticamente toda composta pelas chamadas salas limpas ou classificadas, onde todo o ar proveneinte do ambiente externo deve ser filtrado, segregado e constantemente monitorado quanto ao número de partículas em suspensão. É imprescindível a disponibilidade de utilidades, tais como, vapor limpo de grau farmacêutico e água para produção de injetáveis (WFI). A qualidade dos fluídos dos processos, os equipamentos que os geram e as tubulações devem ser compostas por materiais cada vez mais nobres e compatíveis com as normas estabelecidas (BARBOSA, 2009).

Quanto às questões de propriedade intelectual, $\mathrm{BC}$ acha que o assunto pode representar uma barreira para utilização das empresas $C M O s$. Na percepção dele ainda há um grau de reputação a ser alcançado por essas empresas de uma forma geral. Isso faz com que diversas companhias ainda prefiram utilizar a expertise de fornecedores para desenvolver um determinado processo em detrimento às CMOs. Os fornecedores têm seu retorno financeiro no desenvolvimento dos processos e na venda dos equipamentos para utilização pelo produtor. As $C M O$ s segundo $\mathrm{BC}$, focam ainda basicamente na entrega do produto, sem necessariamente ter a preocupação com os meios para 
fabricação do mesmo. As CMOs normalmente obtêm suas receitas sobre os royalties da venda do produto pelo contratante. Já na percepção do entrevistado MP, a questão de propriedade intelectual deve ser tratada logo no primeiro momento através de um Contrato de Confidencialidade claro, transparente e com responsabilidades definidas. Para AS, diretor de um conglomerado biotecnológico brasileiro, a questão não é tão preocupante porque essa área é fechada e restrita. A empresa que desrespeitar essa questão está fadada ao fracasso.

Sobre o porte das empresas que desverticalizam, os entrevistados AC, BC e TM opinaram que geralmente as pequenas companhias, conhecidas como startups, desenvolvem produtos inovadores internamente, testam em estudos clínicos de fase I e II e, por não terem capacidade de produção em larga escala, estabelecem acordos com organizações maiores. As startups acabam faturando na maioria das vezes sobre os royalties dos acordos de venda da tecnologia celebrados com empresas de maior porte (geralmente Bigpharmas) ou, ainda com menor frequência, firmando contratos com CMOs para terceirização da produção em larga escala.

Recentemente, diversos fundos de investimentos têm sido disponibilizados às pequenas startups. Por consequência disso essas empresas têm conseguido estabelecer parcerias com as $C M O \mathrm{~s}$ da área sem necessariamente ter que vender a tecnologia desenvolvida ou negociar a própria empresa para organizações maiores. De acordo com a maior parte dos entrevistados, enquanto as pequenas startups geralmente buscam as $C M O$ s por não terem capacidade de produção (o escopo delas não é produzir em larga escala), as empresas maiores procuram desverticalizar para reduzir seus custos ou focar em atividades consideradas principais.

Na opinião da entrevistada CA, o tamanho ou porte de uma empresa não tem relação direta com a decisão de desverticalizar. Para ela, esse movimento ocorre mais frequentemente pelas estratégias das empresas do que propriamente pelo seu porte. Da mesma opinião compartilha o entrevistado MP que enxerga o movimento ocorrendo independente do porte de empresas. Segundo ele, a empresa pequena pode procurar a grande para fabricação de seus produtos desenvolvidos, quanto a maior pode contratar outra grande para terceirização das atividades necessárias. Ainda sobre o assunto, o entrevistado LP opina que as companhias de grande porte ainda têm maior potencial para estabelecer e conduzir processos de terceirização porque têm maiores condições de investir no mercado.

Em relação à localização geográfica onde a desverticalização é percebida, na visão da maioria dos gestores o movimento é muito comum nos Estados Unidos (EUA), na Europa (principalmente França e Alemanha) e em alguns países da Ásia (Coreia do Sul, Índia, Singapura, China e Malásia foram citados). Na opinião do entrevistado $\mathrm{BC}$, o mercado asiático e o europeu estão muito aquecidos. Algumas empresas asiáticas, tais como Samsung e Celta, seguem expandindo nessa área, focadas principalmente em pesquisa. Para a entrevistada CA, nos países desenvolvidos verifica-se mais intensamente o fenômeno da desverticalização pelo fato de existirem mais instalações fabris qualificadas e, portanto, com maior disponibilidade para terceirização de atividades de produção. $\mathrm{O}$ entrevistado LP acrescenta que o movimento tende a ocorrer em regiões com necessidade de investimentos menores e fatores fiscais, tributários e logísticos favoráveis.

$\mathrm{O}$ entrevistado AC observou ainda que o mercado dos EUA é enorme e muitas vezes as empresas não conseguem atender à demanda interna e mundial. Uma das consequências disso é a necessidade estratégica de licenciar e certificar empresas $C M O$ s de outros países para suprir esse mercado. Na percepção dele, esse movimento está crescendo na Ásia, sendo impulsionado principalmente pela mão de obra barata e pela excelente velocidade de resposta. Assim como outros entrevistados, AC pontuou que o principal problema das indústrias asiáticas permanece sendo a incerteza quanto à segurança, confiabilidade e qualidade. Segundo ele, é importante que as empresas encaminhem técnicos para certificar as $C M O$ s asiáticas antes de firmarem parcerias com as mesmas.

Embora os EUA ainda detenham mais de $40 \%$ do mercado na área, recentemente a pressão por custos de fabricação menores tem impulsionado os prestadores de serviços a estabelecerem suas instalações em países emergentes. Apoiados e incentivados pelos governos locais, além de estimulados pela crescente disponibilidade de oportunidades de financiamento, a quantidade de indústrias biofarmacêuticas - incluindo CMOs - se estabelecendo em países como China e Índia, está crescendo rapidamente. Nessas regiões, uma grande variedade de biomedicamentos, incluindo diversas proteínas recombinantes e anticorpos monoclonais (mAbs) está sendo desenvolvida, produzida e comercializada para o mercado local e externo (ZHANG, 2015). A opção na Ásia para terceirizar projetos a baixo 
custo - particularmente em produção de larga escala - tem se tornado cada vez mais valiosa e vem impactando na distribuição das empresas CMOs pelo mundo (SPECIAL REPORT, 2011).

Atualmente a Índia, por exemplo, é o país que possui mais instalações aprovadas para produção de medicamentos pelo FDA fora dos EUA. As leis de patentes indianas foram alteradas em Março de 2005 e abriram um novo caminho para esse mercado. A construção de uma planta biofarmacêutica no país custa em média $40 \%$ a menos do que na Europa. Nesse cenário, a competitividade da Índia está crescendo, com disponibilidade de inúmeras empresas de outsourcing para desenvolvimento e produção de vacinas e biossimilares. As empresas indianas possuem o maior número de submissões de Drug Master Files (DMF) dos seus produtos pleiteando aprovação, registro e autorização do FDA para comercialização na América (GOMES, 2014).

$\mathrm{O}$ entrevistado JCF observou que tem dificuldade em enxergar a geografia como um elemento na origem da terceirização. Na visão dele, depende do que o contratante esteja solicitando e de onde será utilizado o produto de uma determinada $C M O$. É possível, por exemplo, solicitar produtos fabricados em $C M O$ s não tão conceituadas de países em desenvolvimento para utilização em locais sem necessidade de certificações mais rigorosas. Esses produtos podem não oferecer um grau de confiabilidade elevado, porém numa situação emergencial é importante poder contar com eles. Segundo JCF, uma das missões da empresa onde atua é alcançar o maior número de pessoas em todos os países do globo. Para tanto, as estratégias adotadas são diferentes em países desenvolvidos e em desenvolvimento. Nos países em desenvolvimento é interessante para a empresa firmar parceria com institutos produtores (funcionariam nesse caso como $C M O s$ ) visando obter vantagens em volume produzido (escala) e capacidade de produção. Dessa forma, a empresa consegue atingir a um quantitativo de pessoas que provavelmente não teria acesso a esse tipo de produto, suprindo o mercado dos países mais pobres, praticando preços menores, obtendo margens de lucro mais curtas, porém atendendo a um público maior.

Quanto ao Brasil, a maioria dos entrevistados apontou que o fenômeno da desverticalização de biomedicamentos ainda é incipiente. Para o entrevistado RD, as empresas nacionais precisam inicialmente aprender a verticalizar (produzir biomedicamentos internamente) para então pensar em desverticalizar. Na percepção dele, há ainda poucos cursos de biotecnologia formando profissionais capacitados para o mercado, tendo faltado durante anos uma política que impulsionasse a expansão dessa área. Na indústria farmoquímica o país aprendeu a produzir (depois de anos), porém no campo biofarmacêutico ainda há um longo caminho a percorrer. Na opinião de AS, não seria tão interessante para o Brasil fomentar o mercado interno de empresas $C M O$ s. Segundo ele, seria importante uma legislação menos restritiva quanto à terceirização de uma forma geral, com um afrouxamento nas taxas fiscais consideradas altas. Esses fatores, na percepção dele, são os principais impeditivos para que as empresas brasileiras recorram às $C M O$ s já existentes no mundo ("global players"). Para MP, embora a desverticalização no Brasil esteja crescendo de maneira exponencial na área de farmoquímicos, ainda é pouco comum para biomedicamentos. O entrevistado LP, ainda não enxerga no Brasil uma tendência à desverticalização. Ele pontuou que observa claramente a desconcentração da produção, onde as empresas globais escolhem locais estratégicos no Brasil para produção dos seus produtos, mas não a ocorrência do fenômeno da desverticalização. Para ele o país ainda precisa contar com empresas prestadoras de serviços capacitadas e detentoras de conhecimento tecnológico suficiente para reproduzir processos biológicos complexos. Talvez por consequência da incipiência brasileira na produção de biomedicamentos, foi possível constatar nas entrevistas com alguns atores nacionais que ainda existe um certo desconhecimento em relação à prestação de serviços nessa área. Tal fato resultou em dificuldades nas respostas aos questionamentos realizados.

\section{Considerações Finais}

Através da literatura e das informações coletadas em campo, pode-se afirmar que em um contexto global, há uma tendência à ocorrência do fenômeno da desverticalização em empresas produtoras de biomedicamentos. Na percepção dos participantes, o movimento pode ser influenciado por diversos fatores e circunstâncias, sobretudo os relacionados ao custo, à manutenção no foco nas atividades principais, ao ganho de flexibilidade operacional ou ao estabelecimento de estratégias de longo prazo. Além desses, outros fatores e circunstâncias foram também citados com frequência pelos especialistas, tais como, mitigação de riscos (divisão de responsabilidades), ganho de velocidade de 
produção, acesso a competências externas, dentre outros. Embora a qualidade não tenha sido considerada como um fator que estimule fortemente o movimento de desverticalização de atividades produtivas na área, a importância da terceirização realizada com qualidade foi reforçada pela maioria dos entrevistados, considerando as rigorosas questões regulatórias da área e a reputação das companhias envolvidas no contrato de prestação de de serviços.

Considerando o ciclo de produção clássico de biomedicamentos, ainda que não tenha ocorrido consenso absoluto, o entendimento da maioria dos entrevistados foi de que o fenômeno acontece mais significativamente nas atividades de scale-up/produção dos lotes para ensaios clínicos de fase III, seguido de perto pelas etapas de processamento final e com menor frequência nas atividades de produção da IFA para comercialização (pós-registro). As atividades de scale-up/produção dos lotes para ensaios clínicos de fase III geralmente ocorrem em fases pré-registro do produto, onde as empresas ainda têm um nível de incerteza elevado quanto à aprovação do biomedicamento e podem optar pela contratação para compartilhamento do risco de insucesso. Além disso, nem sempre as organizações possuem espaço em sua programação de produção para encaixar lotes não destinados à comercialização. Sobre as atividades de processamento final, essas geralmente não possuem alto grau de conhecimento tácito envolvido e esse fato pode impulsionar a terceirização. Por conta da menor complexidade, para essas atividades há um número considerável de prestadores oferecendo esses serviços. Por outro lado, as atividades para fabricação das IFAs, consideradas centrais para as empresas, são geralmente realizadas internamente em função do elevado grau de expertise tecnológica envolvido. No setor biofarmacêutico, as atividades relacionadas à produção da IFA para fins de comercialização envolvem ativos altamente específicos, requerendo mão de obra especializada e gerando maior valor agregado ao produto.

Os entrevistados reforçaram a necessidade do estabelecimento de processos sistemáticos eficazes destinados à avaliação e a seleção de empresas prestadoras de serviços disponíveis na área no momento da contratação. A análise deve levar em consideração diversos aspectos que possam atenuar as possíveis dificuldades a serem encontradas na utilização de $C M O$ s, tais como, capacitações e experiência da empresa em processos biotecnológicos, infraestrutura existente nas plantas industriais, envolvimento de todos os níveis gerenciais de ambas as empresas no projeto de terceirização, divergências entre os interesses da organização contratante e da prestadora de serviço, atendimento às exigências regulatórias, dentre outros fatores descritos ao longo do trabalho. A importância da elaboração de contratos claros, transparentes e com marcos e responsabilidades bem definidos é de fundamental importância no processo de desverticalização e terceirização de atividades.

Em geral, os participantes também pontuaram que percebem grandes diferenças quanto à frequência da desverticalização na indústria de biomedicamentos para o setor farmoquímico. Essas diferenças podem ser atribuídas ao nível de complexidade das operações para produção de biomedicamentos (concebida em organismos vivos) e ao rigor das exigências regulatórias. Por conta desses fatores as empresas biofarmacêuticas ainda possuem tendência maior de realizar suas atividades produtivas internamente do que as farmoquímicas. Há um entendimento também de que o fenômeno ocorre tanto nas empresas de grande porte, quanto nas menores que geralmente recorrem à terceirização por não possuírem capacidade para produção em larga escala. A maioria dos entrevistados observou que embora o fenômeno seja ainda mais observado em países desenvolvidos, principalmente EUA e Europa (sobretudo Alemanha e França), os países asiáticos (Índia, China, Coréia e Singapura) têm apresentado forte crescimento no mercado de terceirização biofarmacêutico. No Brasil, a desverticalização já ocorre no campo da indústria farmoquímica, porém praticamente não é observada para biomedicamentos.

Conclusivamente, pode-se considerar que os processos decisórios para desverticalizar atividades produtivas em empresas biofarmacêuticas devem ser avaliados cuidadosamente e dependem de uma série diversificada de fatores e circunstâncias, combinados ou não dependendo do caso, conforme descrito ao longo do estudo. A discussão sobre os resultados obtidos no estudo poderá contribuir não somente para a avaliação da posição estratégica de uma organização da área em relação às oportunidades de terceirizar suas atividades, como também para propor melhorias em parcerias já existentes.

É importante ressaltar também que o tema central tratado pelo estudo pode ser considerado inédito e pioneiro em relação à academia, sobretudo no que se refere à realidade brasileira, onde há ainda poucas empresas atuando na área de produção de biomedicamentos. Tal fato pode ser 
comprovado pelos escassos trabalhos científicos identificados na literatura relacionados à desverticalização de atividades produtivas em empresas de biomedicamentos. Ainda que existam trabalhos citando a desverticalização na indústria farmacêutica, esses não tratam do fenômeno voltado especificamente para o setor de produção de biomedicamentos.

Considerando-se todo esse contexto, abre-se a oportunidade para novos estudos objetivando um entendimento mais aprofundado sobre o assunto. Dentre as propostas, recomenda-se, por exemplo:

Estudar com profundidade casos de empresas do setor que utilizam ou prestam serviços relacionados à produção de biomedicamentos;

Pesquisar sobre o ganho em desempenho das empresas da área que optam por desverticalizar suas etapas de produção;

Estudar as principais dificuldades e limitações encontradas para o estabelecimento e cumprimento dos contratos de terceirização celebrados na área de produção de biomedicamentos;

Referências

ALKERMES. Outsourcing in the Pharma Industry - Experience, Expertise and Enthusiasm. Disponível

http://www.alkermes.com/assets/content/files/Partnership_Whitepaper_August_2012.pdf.

Acesso em 15/12/2012

ALONSO-CAPLEN, F. Vaccine Manufacturing Outsourcing. 2013 Annual PDA (Parenteral Drug Association) Meeting.Orlando, Miami, USA. 16-Apr-2013.

BAETAS, R.B.C. Modelo de Análise de Indústria Baseada em Ciências: $O$ caso da indústria brasileira de vacinas de uso humano. Tese de D.Sc., Processos Químicos e Bioquímicos - Escola de Química/UFRJ, RJ, 2004.

BARBOSA, A.P.R. A formação de competências para inovar através de processos de transferência de tecnologia: um estudo de caso. Tese (Doutorado em Tecnologia de Processos Químicos e Bioquímicos) - Universidade Federal do Rio de Janeiro, Escola de Química, Rio de Janeiro, 2009.

CANDELORO, R..J; DOS SANTOS, V. Trabalhos acadêmicos uma orientação para a pesquisa e normas técnicas. Porto Alegre: Editora Age Ltda, 2006.

CHATURVEDI, S. Outsourcing in Pharmaceutical Industry. Analyst-Healthcare Practice. Frost \& Sullivan em: http://www.bionity.com/en/whitepapers/49803/outsourcing-in-pharmaceuticalindustry.html. Acesso em: 05/04/2014.

COPANI, G., URGO, M. New business models and configuration approaches for focused-flexibility manufacturing systems. 1st CIRP Global Web Conference: Interdisciplinary Research in Production Engineering. Procedia CIRP 2, 10- 15, 2012.

FRANÇOSO, M. S.; STRACHMAN, E. A indústria farmacêutica no Brasil e na Índia: um estudo comparativo. Revista de Economia, Editora UFPR, jan./abr. 2013, v. 39, n. 1 (ano 37), p. 91-112.

GERALDI, A. H. A terceirização na produção de medicamentos. 2010. Instituto Racine. Disponível em: http://www.racine.com.br/portal-racine/setor\%20industrial/terceirizacao/aterceirizacao-na-producao-de-medicamentos-dp3. Acesso em: 10 de setembro de 2014.

GOMES, E.B.P. Clusters e biotecnologia para a superação da imitação: estudo de caso da indústria farmacêutica brasileira. Tese (doutorado) - Universidade Federal do Rio de Janeiro, Instituto de Economia, Programa de Pós-Graduação em Políticas Públicas, Estratégias e Desenvolvimento, e Universidade Estadual de Goiás, 2014. 
KOLAR, G.R. Outsourcing: route to a new pharmacy practice model. Am J Health-Syst Pharm.; 54:48-52, 1997.

LANTHIER, M.; BEHRMAN, R.; NARDINELLI, C. Economic issues with follow on protein products. Nature Reviews - Drug Discovery, 7, 733-737, 2008.

MADEIRA, L.S. Prospecção tecnológica através de depósitos de patentes para produção de proteínas terapêuticas de interesse brasileiro. Tese de Doutorado em Tecnologia de Processos Químicos e Bioquímicos - Universidade Federal do Rio de Janeiro, Escola de Química, Rio de Janeiro, 2013.

NAVARRO, L.L.L. Estudo sobre o projeto de redes de atenção a pacientes com câncer residentes em regiões remotas. Tese de Doutorado - UFRJ / COPPE / Programa de Engenharia de Produção. Rio de Janeiro, 2015.

NEHA, A.; NAGEEN, A.; HIMANSHI, K.; PARINITA, K; TARUN, G. Contract research organization and its growth. IOSR Journal of Pharmacy, Mar.-Apr. 2012, Vol. 2(2) pp: 182-183.

OLIVEIRA, J.F.G.; TELLES, L.O. O papel dos institutos públicos de pesquisa na aceleração do processo de inovação empresarial no Brasil. Rev. USP, No. 89, SP, 2011.

REZAIE, R.; FREW, S. E.; SAMMUT, S. M.; MALIAKKAL, M. R.; DAAR, A. S.; SINGER, P. A. Brazilian health biotech-fostering crosstalk between public and private sectors. Nature Biotechnology, Vol. 26, No. 6, pp. 627-644, 2008.

SCARAMUZZO, M. Laboratórios terceirizam produção de remédios. 2012. Disponível em: http://www.tudofarma.com.br/noticias/noticiasInterna.asp?Textos_ID=25277. Acesso em: 18 de Novembro 2012.

SCHACHTER, B. Partnering with the professor. Nature Biotechnology, Vol.30, No.10, pp. 944952, 2012.

SILVA, E.; MENEZES, E.M. Metodologia da pesquisa e elaboração de dissertação. 3. ed., Florianópolis: Laboratório de Ensino a Distância da UFSC, 2001.

SPECIAL REPORT. Global Contract Manufacturing Companies - Pharmaceutical and Bitechnology - $2011 . \quad$ Disponível em: http://www.paragonbioservices.com/LinkClick.aspx?fileticket=CYCb05Z6DIQ\%3D\&tabid=137 . Acesso: em 14 de Abril de 2015.

TILLOTS PHARMA. Disponível em: http://www.tillotts.com/. Acesso em Novembro de 2013.

WONGTSCHOWSKI, P. Indústria Química - Riscos e Oportunidades. Editora Edgard Blücher LTDA - 2 edição, 2002.

ZHANG, J.J. The Global Biomanufacturing Outsourcing Market. BioPharmInternational.Volume 28, Issue 3. Fevereiro de 2015. 